\title{
Experimental investigation of direct myocardial protective effect of atrial natriuretic peptide in cardiac surgery
}

\author{
Shinji Wakui, MD, ${ }^{\text {a,b,d }}$ Akira Sezai, MD, PhD, ${ }^{\mathrm{b}}$ Gero Tenderich, MD, PhD, ${ }^{\mathrm{d}}$ Mitsumasa Hata, MD, PhD, \\ Syunji Osaka, ${ }^{\mathrm{b}}$ Yoshiki Taniguchi, ${ }^{\mathrm{c}}$ Reiner Koerfer, MD, PhD,${ }^{\mathrm{d}}$ and Kazutomo Minami, MD, PhD ${ }^{\mathrm{a}, \mathrm{b}, \mathrm{d}}$
}

\begin{abstract}
Objective: Human atrial natriuretic peptide has recently become known not only as a heart failure drug but also for myocardial protection. We investigated its direct myocardial protective effect on ischemia-reperfusion injury in cardiac surgery.
\end{abstract}

\begin{abstract}
Methods: Male pigs (35-45 kg) undergoing surgery with cardiopulmonary bypass, with 60-minute reperfusion after 30-minute cardioplegia, were grouped by timing of atrial natriuretic peptide administration: group $\mathrm{C}(\mathrm{n}=8)$, no atrial natriuretic peptide (cardioplegia only); group H1 $(\mathrm{n}=8) ; 100-\mu \mathrm{g}$ atrial natriuretic peptide administration after aortic crossclamping; group $\mathrm{H} 2(\mathrm{n}=8)$, administration before aortic declamping; and group $\mathrm{H} 1+\mathrm{H} 2$ $(\mathrm{n}=8)$, administration both after crossclamping and before declamping. Blood and myocardial cyclic guanosine monophosphate, calcium, and residual adenosine triphosphate levels were determined. Histologic investigation was conducted by electron and optical microscopy.
\end{abstract}

Results: Atrial natriuretic peptide increased blood and myocardial cyclic guanosine monophosphate levels $(P<.0001, P<.0001, P<.007 \mathrm{H} 1+\mathrm{H} 2$ vs $\mathrm{C} ; P<.0014, P<.0007, P<.003 \mathrm{H} 1$ vs $\mathrm{C})$, decreased myocardial calcium $(P<.0038 \mathrm{H} 1+\mathrm{H} 2$ vs $\mathrm{C})$, and increased myocardial residual adenosine triphosphate. Electron microscopy revealed ischemic changes in mitochondria and nuclei in group $\mathrm{C}$ but not in treatment groups.

Conclusions: Ischemia-reperfusion injury was inhibited with equal effectiveness by atrial natriuretic peptide both during ischemia and immediately before reperfusion, acting directly on myocardium through cyclic guanosine monophosphate. Atrial natriuretic peptide may be useful as a supportive measure for patients with long aortic crossclamping time or difficulties in weaning from cardiopulmonary bypass. (J Thorac Cardiovasc Surg 2010;139:918-25)

Atrial natriuretic peptide (ANP) was isolated and identified in 1984 by Kangawa and Matsuo. ${ }^{1}$ It is predominantly synthesized in the atrium and involved in the regulation of body fluid and circulation. A human atrial natriuretic peptide (hANP) preparation, carperitide, was developed and has been used mainly for treatment of heart failure because it improves preload and afterload by diuresis ${ }^{2,3}$ and vasodilatation. $^{4-6}$ In the past 25 years, studies have revealed the role of ANP in cardiovascular endocrinologic systems and elucidated the details of its metabolism. It has been demonstrated to exert various effects, including inhibition of reninangiotensin, myocardial hypertrophy, and fibrosis. ${ }^{7-11}$

During cardiac operations performed at our department, we have achieved satisfactory results in overcoming the

\footnotetext{
From Advanced Research Institute for the Sciences and Humanity (ARISH) and the Departments of Cardiovascular Surgery, ${ }^{\mathrm{b}}$ and Collaboration, ${ }^{\mathrm{c}}$ Nihon University, Tokyo, Japan, and the Department of Thoracic and Cardiovascular Surgery, Heart Center North-Rhine-Westphalia, ${ }^{\mathrm{d}}$ Ruhr University of Bochum, Bad Oeynhausen, Germany.

Disclosures: None.

Received for publication Nov 23, 2008; revisions received July 26, 2009; accepted for publication Aug 9, 2009; available ahead of print Nov 12, 2009.

Address for reprints: Shinji Wakui, MD, Herz- und Diabeteszentrum NRW, RuhrUniversität Bochum, Georgstraße 11, 32545 Bad Oeynhausen, Germany (E-mail: wakui.shinji@googlemail.com).

0022-5223/\$36.00

Copyright (c) 2010 by The American Association for Thoracic Surgery doi: $10.1016 /$ j.jtcvs. 2009.08 .030
}

disadvantages of cardiopulmonary bypass (CPB), which include such complications as decreased urinary output and third-space fluid shift, by administering an intravenous infusion of ANP at a low dose (0.02-0.05 $\gamma$ ) when CPB was commenced. ${ }^{12}$ In addition, it has been recognized that ANP decreases the demand for furosemide and inhibits loss of potassium, deterioration in electrolyte balance, and development of arrhythmias during unstable conditions after surgery. ${ }^{13,14}$ ANP has become a useful drug for perioperative and postoperative management in our department.

Recent studies demonstrated that ANP exerts various actions. It has been reported that ANP inhibits volume overload-related factors and vasopressive factors (sympathetic nervous system, renin-angiotensin system, endothelin-1, inflammatory cytokines, tumor necrosis factor $\alpha$, and interleukin 6) referred to as cardiotoxic factors. ${ }^{15,16}$ It has also been reported that ANP exerts coronary vasodilatation when administered into the coronary artery during percutaneous transluminal coronary angioplasty and inhibits myocardial remodeling in remote areas afterward. ${ }^{17}$ These studies suggest that ANP exerts myocardial protection.

It has also been demonstrated at our institution that ANP inhibits ischemia-reperfusion injury by inhibition of an increase in myocardial calcium concentration. In addition, our institution has already reported that intracoronary administration of ANP to pig hearts as an adjuvant to 

Abbreviations and Acronyms
ANP = atrial natriuretic peptide
ATP $=$ adenosine triphosphate
cGMP $=$ cyclic guanosine monophosphate
$\mathrm{CPB}=$ cardiopulmonary bypass
hANP $=$ human atrial natriuretic peptide

cardioplegia increases myocardial cyclic guanidine monophosphate (cGMP) level after reperfusion and decreases myocardial calcium level, leading to relief of ischemiareperfusion injury. This indicates a potential of direct myocardial protective effect of ANP. ${ }^{18}$

This study aimed to reveal the detailed mechanism of direct myocardial protective effect of ANP by comparing timing variations of ANP administration.

\section{MATERIALS AND METHODS}

Thirty-two male pigs (weight $40.8 \pm 2.7 \mathrm{~kg}$ ) were used for the experiments. All animals received humane care in accordance with the "Principles of Laboratory Animal Care" and the "Guide for the Care and Use of Laboratory Animals" (www.nap.edu/catalog/5140.html). An arterial line was established into the right common carotid artery and a thermodilution catheter was introduced into the right external jugular vein for monitoring of arterial pressure, central venous pressure, and pulmonary arterial pressure. Limb-lead electrocardiography was also monitored. After endotracheal intubation, animals were ventilated with a tidal volume of 10 to 15 $\mathrm{mL} / \mathrm{kg}$ and a rate of 20 to 25 breaths/min with a respirator (Servo $900 \mathrm{E}$; Siemens-Elema AB, Solna, Sweden) maintaining percutaneous oxygen saturation at $95 \%$ to $100 \%$. A catheter (CX-654U; Cathex Co, Ltd, Tokyo, Japan) was placed in the coronary sinus through the left internal jugular vein for blood collection. The thorax was opened by median sternotomy. A cannula (TF-024L; Edwards Lifesciences Research Medical, Midvale, Utah) was inserted into the right atrium for the inferior vena cava, and another cannula (A211-5.2; Stockert Instrumente GmbH, Munich, Germany) was inserted into the ascending aorta for blood perfusion. The CPB was prepared with a gyropump (Kyocera Corp, Kyoto, Japan) and an oxygenator (HPO-20H-C; Senko Ika Kogyo [Mera], Tokyo, Japan). In addition, a cannula (Medtronic, Inc, Minneapolis, Minn) was inserted into the aortic root for perfusion of a cardioplegic solution and venting. CPB was started at $37^{\circ} \mathrm{C}$. After the ascending aorta was clamped, a cold $\left(4^{\circ} \mathrm{C}\right)$ cardioplegic solution (Miotecter; Mochida Pharmaceutical Co, Ltd, Tokyo, Japan) was infused $(20 \mathrm{~mL} / \mathrm{kg})$ through the cannula inserted into the aortic root to achieve cardioplegic arrest for 30 minutes. Thereafter, the aortic clamping was released and reperfusion started. After reperfusion was continued for 60 minutes, animals were weaned from CPB (Figure 1).

\section{Experimental Groups}

Animals were divided into 4 groups according to the timing of ANP infusion: the control group (group C) consisted of 8 animals treated only with a cardioplegic solution (Miotecter) after clamping of the ascending aorta; the postclamping group (group H1) consisted of 8 animals treated with ANP at a dose of $100 \mu \mathrm{g}$ followed by Miotecter after aortic crossclamping; the predeclamping group (group H2) consisted of 8 animals treated with ANP at a dose of $100 \mu \mathrm{g}$ before aortic declamping; and the combined group (group $\mathrm{H} 1+\mathrm{H} 2$ ) consisted of 8 animals treated with ANP at a dose of $100 \mu \mathrm{g}$ timed both after aortic crossclamping and before aortic declamping (Figure 1).

\section{ANP Administration Method}

The hANP was bolus infused into the aorta near the cardioplegic aorta cannula with a syringe with a 27 -gauge needle.

\section{Specimen Collection Method}

Blood specimens were collected from the catheter placed in the coronary sinus at 4 time points: before the $\mathrm{CPB}$ (pre-CPB), immediately after aortic declamping (start reperfusion), 30 minutes after the start of reperfusion (reperfusion $30 \mathrm{~min}$ ), and after the completion of reperfusion (post-CPB; Figure 1). In the collected blood specimens, cGMP was measured. For determination of myocardial calcium, cGMP, and residual adenosine triphosphate (ATP) levels, specimens of the myocardium were collected after the completion of reperfusion by cutting off the muscle around the diagonal branch; the myocardium was isolated from the inside of the inner membrane (Figure 1). A portion of each specimen was immediately frozen with liquid nitrogen. After 0.1-N hydrochloric acid cooled in ice was added to the frozen specimen, the myocardial specimen was homogenized. The homogenate was centrifuged at $13,000 \mathrm{rpm}$ and $4^{\circ} \mathrm{C}$ for 40 minutes, and the supernatant was used as a sample for determination of myocardial calcium, cGMP, and residual ATP levels. Calcium concentration was measured by atomic absorption spectrophotometry with a Hitachi Z-6100 analyzer (Hitachi, Ltd, Tokyo, Japan); cGMP concentration was measured with a YAMASA Cyclic GMP Assay Kit (Yamasa Corp, Chiba, Japan); and ATP was measured by the firefly luciferin-luciferase method with a KIKKOMAN ATP assay kit (KIKKOMAN, Ltd, Tokyo, Japan).

\section{Electron Microscopic Observation Method}

Another portion of each specimen was examined microscopically. For microscopy, the specimen was fixed with a $2.5 \%$ glutaraldehyde fixative at $4{ }^{\circ} \mathrm{C}$ for 12 hours. After that, it was dehydrated in ethanol and then propylene oxide, and embedded in Quetol 812 (Nissin EM Co, Ltd, Tokyo, Japan). The embedded specimen was sectioned with an Ultracut UCT ultramicrotome (Leica Microsystems, Vienna, Austria) to prepare semiultrathin sections and ultrathin sections.

\section{Optimal Microscopic Observation Method of Myocardial Ischemic Changes}

The semiultrathin sections were stained with toluidine blue and observed with a light microscope to examine nuclear chromatin in myocardial cells. Nuclear chromatin was classified into 4 grades, as specified in Figure 7 , and ischemic changes were assessed quantitatively according to the chromatin count in each treatment group. The ultrathin sections were double stained with uranyl acetate and lead citrate and observed with an electron microscope (JEM 1200EX; JEOL Ltd, Tokyo, Japan).

All microscopic examinations were performed by observers blinded to ANP treatment group.

\section{Statistics}

The experimental results were expressed as mean $\pm \mathrm{SD}$. The paired $t$ test and 1-factor analysis of variance were applied to test statistical significance of differences. When a value was determined to be significant by 1 -factor analysis of variance, the Scheffé method was used to analyze the relationship further.

\section{RESULTS}

\section{Hemodynamics}

No significant differences in aortic pressure were observed among the 4 groups either before CPB (103.9 \pm $19.1 \mathrm{~mm} \mathrm{Hg}$ for group $\mathrm{H1}, 100.9 \pm 19.6 \mathrm{~mm} \mathrm{Hg}$ for group $\mathrm{H} 2,97.9 \pm 17.6 \mathrm{~mm} \mathrm{Hg}$ for group $\mathrm{H} 1+\mathrm{H} 2,98.4 \pm 23.1 \mathrm{~mm}$ $\mathrm{Hg}$ for group $\mathrm{C})$ or after $\mathrm{CPB}(84.3 \pm 11.5 \mathrm{~mm} \mathrm{Hg}$ for group 


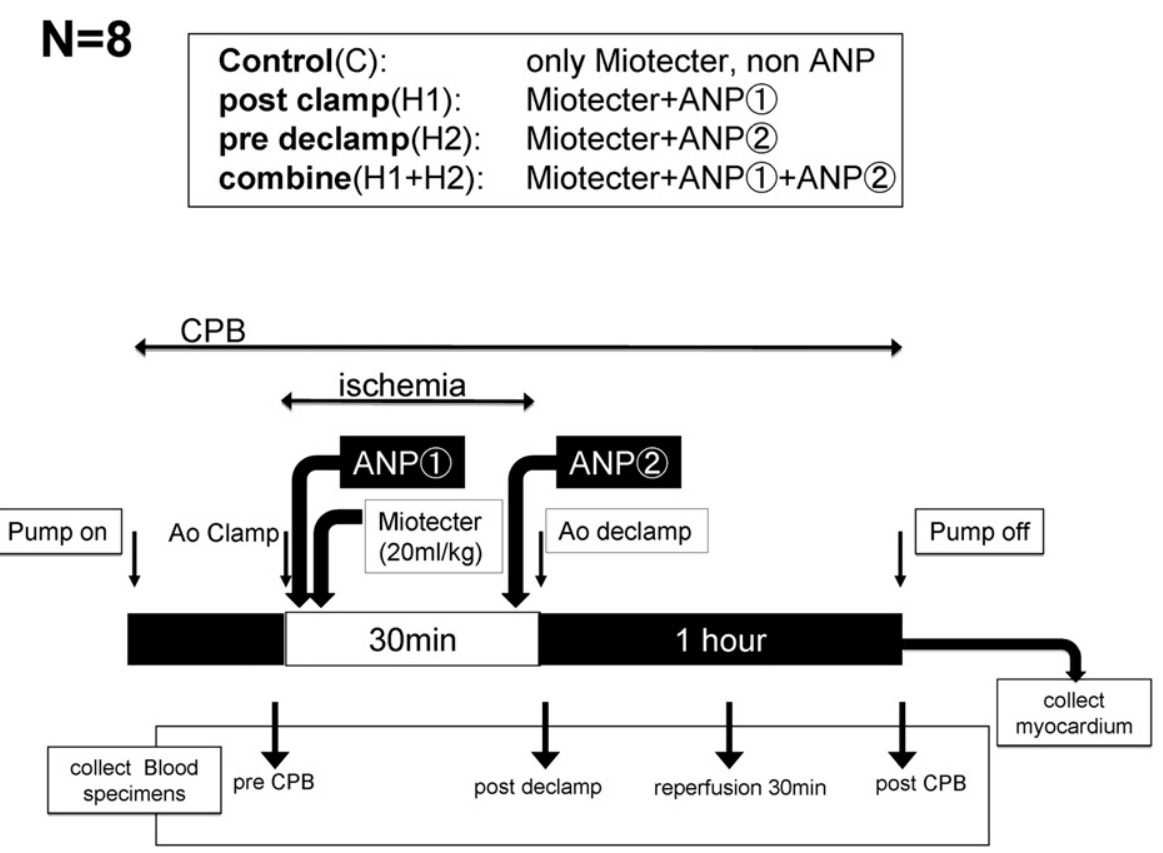

FIGURE 1. Experimental method and groups. Thirty-two pigs underwent surgery with cardiopulmonary bypass $(C P B)$ and were divided into 4 groups according to timing of atrial natriuretic peptide $(A N P)$ administration. In group $\mathrm{C}(\mathrm{n}=8)$, there was no use of atrial natriuretic peptide after aortic $(A o)$ crossclamping; only cardioplegia (Miotecter; Mochida Pharmaceutical Co, Ltd, Tokyo, Japan) was used. After 30 minutes of cardioplegia, reperfusion was performed for 60 minutes. In group $\mathrm{H} 1(\mathrm{n}=8)$, atrial natriuretic peptide $(100 \mu \mathrm{g})$ was administered after aortic crossclamping through ascending aorta. In group $\mathrm{H} 2(\mathrm{n}=8)$, atrial natriuretic peptide was administered before aortic declamping. In group $\mathrm{H} 1+\mathrm{H} 2(\mathrm{n}=8)$, atrial natriuretic protein was administered both after aortic crossclamping and before aortic declamping.

$\mathrm{H} 1,79.1 \pm 3.5 \mathrm{~mm} \mathrm{Hg}$ for group $\mathrm{H} 2,83.1 \pm 4.5 \mathrm{~mm} \mathrm{Hg}$ for group $\mathrm{H} 1+\mathrm{H} 2,80.4 \pm 10.1 \mathrm{~mm} \mathrm{Hg}$ for group C). Rectal temperatures of pigs before aortic crossclamping were $36.3^{\circ} \mathrm{C} \pm 0.5^{\circ} \mathrm{C}$ for group $\mathrm{C}, 36.1^{\circ} \mathrm{C} \pm 0.6^{\circ} \mathrm{C}$ for group $\mathrm{H} 1,35.8^{\circ} \mathrm{C} \pm 0.6^{\circ} \mathrm{C}$ for group $\mathrm{H} 2$, and $36.2^{\circ} \mathrm{C} \pm 0.8^{\circ} \mathrm{C}$ for group $\mathrm{H} 1+\mathrm{H} 2$. There were no significant differences among the groups. Myocardial temperatures before aortic

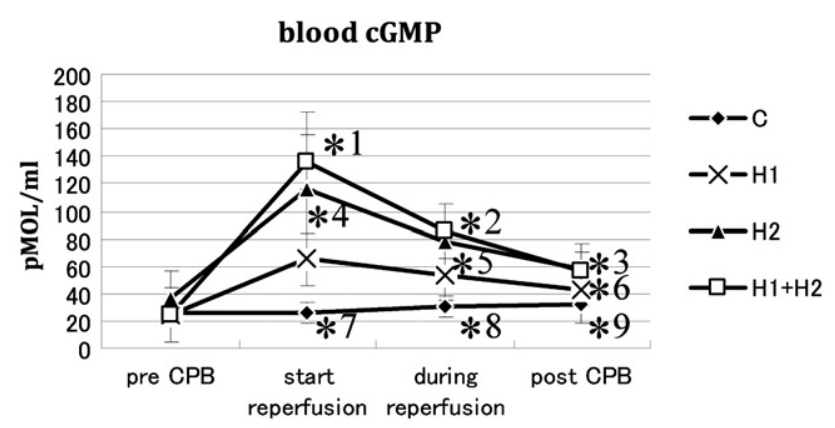

FIGURE 2. Blood cyclic guanosine monophosphate (cGMP) concentrations. Concentrations were significantly increased in groups $\mathrm{H} 1+\mathrm{H} 2$ and H2 relative to group C. $* 1$ indicates $P<.0001$ group $\mathrm{H} 1+\mathrm{H} 2$ versus $\mathrm{C}$; $* 2$ indicates $P<.0001$ group $\mathrm{H} 1+\mathrm{H} 2$ versus $\mathrm{C}$; $* 3$ indicates $P<.007$ group $\mathrm{H} 1+\mathrm{H} 2$ versus $\mathrm{C} ; * 4$ indicates $P<.0014$ group $\mathrm{H} 2$ versus $\mathrm{C} ; * 5$ indicates $P<.0007$ group $\mathrm{H} 2$ versus $\mathrm{C} ; * 6$ indicates $P<.003$ group $\mathrm{H} 2$ versus $\mathrm{C} ; * 7$ indicates $P<.0138$ group $\mathrm{H} 1+\mathrm{H} 2$ versus $\mathrm{H} 1 ; * 8$ indicates $P<.0294$ group $\mathrm{H} 1+\mathrm{H} 2$ versus H1; $* 9$ indicates $P<.0424$ group $\mathrm{H} 1$ versus $\mathrm{H} 2$. declamping were $18.3^{\circ} \mathrm{C} \pm 0.9^{\circ} \mathrm{C}$ for group $\mathrm{C}, 19.1^{\circ} \mathrm{C} \pm$ $0.6^{\circ} \mathrm{C}$ for group $\mathrm{H} 1,19.6^{\circ} \mathrm{C} \pm 0.6^{\circ} \mathrm{C}$ for group $\mathrm{H} 2$, and $18.2^{\circ} \mathrm{C} \pm 0.5^{\circ} \mathrm{C}$ for group $\mathrm{H} 1+\mathrm{H} 2$. There were no significant differences among the groups.

\section{Blood Chemistry}

Blood cGMP concentrations were significantly increased in groups $\mathrm{H} 1+\mathrm{H} 2$ and $\mathrm{H} 2$ relative to those in group $\mathrm{C}$. In group $\mathrm{H} 1+\mathrm{H} 2$, concentrations were $135.6 \pm 51.6 \mathrm{pmol} /$ $\mathrm{mL}$ at the start of reperfusion $(P<.0001), 85.8 \pm 20.2$

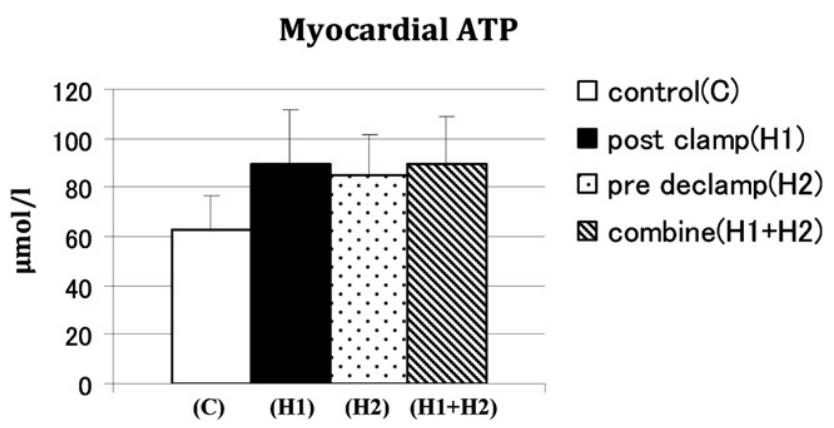

FIGURE 3. Residual myocardial adenosine triphosphate (ATP) levels. No significant differences were observed among treatment groups $(\mathrm{H} 1, \mathrm{H} 2, \mathrm{H} 1$ $+\mathrm{H} 2$ ); however, residual adenosine triphosphate level tended to increase in groups $\mathrm{H} 1, \mathrm{H} 2$, and $\mathrm{H} 1+\mathrm{H} 2$ relative to group $\mathrm{C}$. 


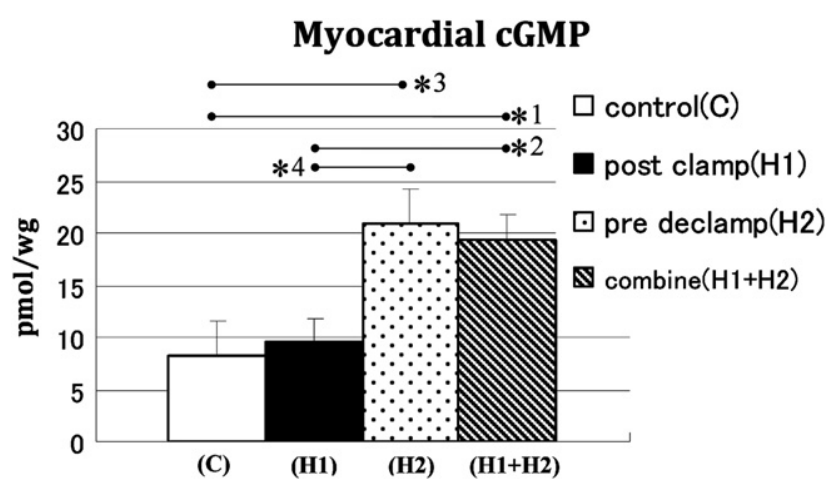

FIGURE 4. Myocardial cyclic guanosine monophosphate (cGMP) concentrations. Concentration was significantly increased in groups $\mathrm{H} 2$ and $\mathrm{H} 1+\mathrm{H} 2$ relative to group $\mathrm{C} . * 1$ indicates $P<.0001 \mathrm{H} 1+\mathrm{H} 2$ versus $\mathrm{C} ; * 2$ indicates $P<.0001 \mathrm{H} 1+\mathrm{H} 2$ versus $\mathrm{H} 1 ; * 3$ indicates $P<.0001 \mathrm{H} 2$ versus $\mathrm{C}$; $* 4$ indicates $P<.0001 \mathrm{H} 2$ versus $\mathrm{H} 1 . w g$, Wet weight in grams.

$\mathrm{pmol} / \mathrm{mL}$ at 30 minutes of reperfusion $(P<.0001)$, and 57.0 $\pm 3.2 \mathrm{pmol} / \mathrm{mL}$ after CPB $(P<.0007)$. In group $\mathrm{H} 2$, concentrations were $115.5 \pm 56.4 \mathrm{pmol} / \mathrm{mL}$ at the start of reperfusion $(P<.0014), 77.8 \pm 27.8 \mathrm{pmol} / \mathrm{mL}$ after $30 \mathrm{~min}$ utes of reperfusion $(P<.0007)$, and $58.4 \pm 11.4 \mathrm{pmol} / \mathrm{mL}$ after CPB $(P<.0003)$. No significant differences were observed between groups $\mathrm{H} 1$ and $\mathrm{C}$, although cGMP concentrations showed a tendency toward increasing in group H1 (Figure 2).

\section{Residual Tissue ATP Levels}

No significant differences in residual ATP level were observed among groups $\mathrm{H} 1, \mathrm{H} 2$, and $\mathrm{H} 1+\mathrm{H} 2$. There was, however, a tendency toward increased residual ATP in groups $\mathrm{H} 1, \mathrm{H} 2$, and $\mathrm{H} 1+\mathrm{H} 2$ relative to group $\mathrm{C}$ : $89.36 \pm$ $22.6 \mu \mathrm{mol} / \mathrm{L}$ for group $\mathrm{H} 1(P<.0587), 84.90 \pm 16.4$ $\mu \mathrm{mol} / \mathrm{L}$ for group $\mathrm{H} 2(P<.1476)$, and $89.73 \pm 19.4 \mu \mathrm{mol} /$ $\mathrm{L}$ for group $\mathrm{H} 1+\mathrm{H} 2(P<.0540)$ versus $62.91 \pm 13.4$ $\mu \mathrm{mol} / \mathrm{L}$ for group $\mathrm{C}$ (Figure 3 ).

\section{Tissue cGMP Concentrations}

The myocardial cGMP concentrations were significantly increased in groups $\mathrm{H} 2$ and $\mathrm{H} 1+\mathrm{H} 2$ relative to group $\mathrm{C}$ : $20.98 \pm 3.17 \mathrm{pmol} / \mathrm{g}$ wet weight for group $\mathrm{H} 2(P<.0001)$ and $19.35 \pm 2.39 \mathrm{pmol} / \mathrm{g}$ wet weight for group $\mathrm{H} 1+\mathrm{H} 2$ $(P<.0001)$ versus $8.23 \pm 4.16 \mathrm{pmol} / \mathrm{g}$ wt weight for group C (Figure 4).

\section{Tissue Calcium Concentrations}

ANP inhibited an increase in calcium concentration: $0.0406 \pm 0.006 \mathrm{mg} / \mathrm{g}$ wet weight for group $\mathrm{H} 1+\mathrm{H} 2$ versus $0.070 \pm 0.020 \mathrm{mg} / \mathrm{g}$ wet weight for group $\mathrm{C}(P<.0038$; Figure 5). In the other ANP treatment groups (H1 and $\mathrm{H} 2$ ), there was no significant difference; however, a tendency

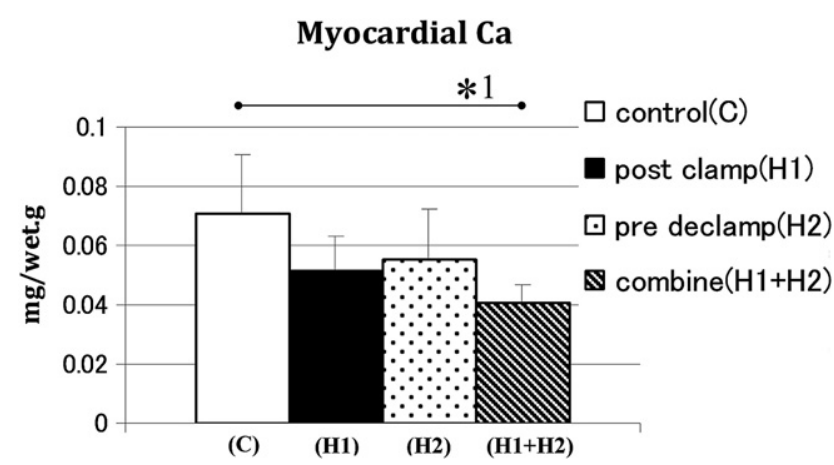

FIGURE 5. Myocardial calcium $(\mathrm{Ca})$ concentration. Increase in concentration was significantly inhibited in group $\mathrm{H} 1+\mathrm{H} 2$ relative to group $\mathrm{C}$. $* 1$ indicates $P<.0038 \mathrm{H} 1+\mathrm{H} 2$ versus C. wetg, Wet weight in grams.

was observed toward inhibition of calcium increase: $0.052 \pm$ $0.012 \mathrm{mg} / \mathrm{g}$ wet weight for group $\mathrm{H} 1(P<.1035)$ and 0.056 $\pm 0.017 \mathrm{mg} / \mathrm{g}$ wet weight for group $\mathrm{H} 2(P<.2673)$. It was predicted that calcium increase would be most inhibited in group $\mathrm{H} 2$, which showed the highest concentration of tissue cGMP, but it was actually inhibited more in group H1.

\section{Electron Microscopic Images}

Mitochondria. Swelling of mitochondria with sparse cristae was observed in group C. In contrast, normal mitochondria were preserved and large amounts of glycogen granules were seen in the ANP treatment groups (Figure 6, A).

Myocardial fibers. Large numbers of thick and fuzzy contraction bands were observed in group C. In contrast, normal distinct myocardial fibers were preserved in the ANP treatment groups (Figure 6, $B$ ).

Myocardial nuclei. Aggregates of nuclear chromatin or aggregations of chromatin around the nuclei were markedly observed in group $\mathrm{C}$. These changes were minor in the ANP treatment groups, however, with the nuclei equivalent to those in nonischemic myocardium (Figure 6, $C$ ).

Electron microscopy revealed a remarkable difference between each of the 3 ANP groups and the control group. It was impossible, however, to determine any differences among the 3 ANP groups.

\section{Toluidine Blue Images}

Ischemic changes in nuclear chromatin were seen on toluidine blue-stained images. In group $\mathrm{C}(\mathrm{n}=8)$, the incidence of mild ischemic change was 44\% (232/522). In contrast, the incidences of normal myocardium in group $\mathrm{H} 1(\mathrm{n}=8)$, group $\mathrm{H} 2(\mathrm{n}=8)$, and group $\mathrm{H} 1+\mathrm{H} 2(\mathrm{n}=8)$ were $57.1 \%$ (285/499), $53.3 \%$ (279/523), and $64.0 \%$ (264/413), respectively, and ischemic changes were inhibited in the ANP treatment groups. Because all 4 groups were treated with a cardioplegic solution, the incidence of irreversible ischemic change was $0 \%$ (Figure 7). 

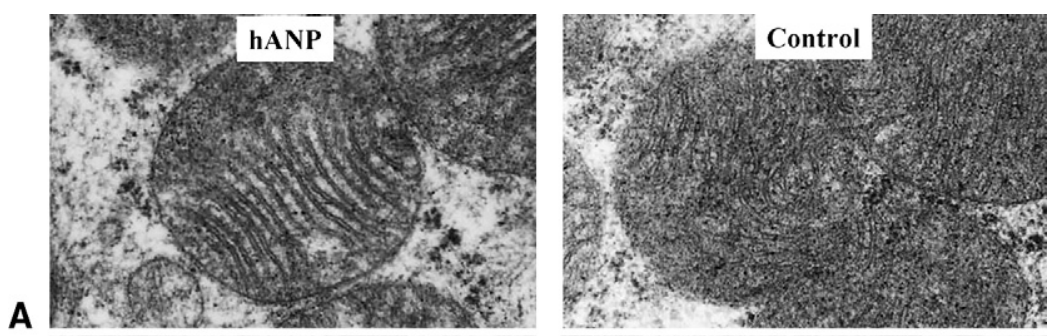

A
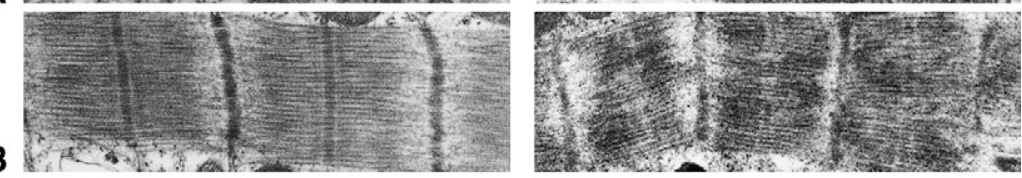

B
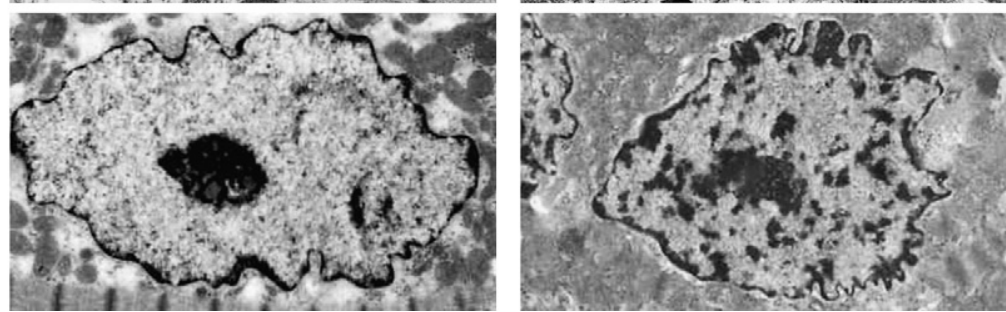

FIGURE 6. Electron microscopic images. A, Mitochondria in electron microscopy. Swelling of mitochondria with sparse cristae was observed in group C. In contrast, normal mitochondria were preserved and large amounts of glycogen granules were seen in human atrial natriuretic peptide $(h A N P)$ treatment groups. B, Myocardial fibers in electron microscopy. Large numbers of thick, fuzzy contraction bands were observed in group C. In contrast, normal distinct myocardial fibers were preserved in treatment groups. C, Myocardial nuclei in electron microscopy. Aggregates of nuclear chromatin or aggregation of chromatin around nuclei were markedly observed in group C; however, these changes were minor in groups, with nuclei equivalent to those in nonischemic myocardium.

\section{DISCUSSION}

In recent years, studies on myocardial protection by ANP have been occasionally reported. These studies have not investigated direct effects of ANP on the myocardium. In most of the studies, the myocardial protection was likely a secondary effect of inhibition of cardiotoxic factors or coronary vasodilatation. In our study, we directly administered hANP into the pig coronary artery, and blood specimens were collected from a catheter inserted into the coronary sinus. Myocardial tissue specimens were also collected to investigate direct effects of ANP on the myocardium.

Kitakaze and colleagues ${ }^{19}$ reported an experiment conducted with a dog ischemia-reperfusion model. The model was prepared by clamping the left anterior descending coronary artery for 90 minutes, followed by reperfusion for 6 hours. The animals received carperitide at $0.1 \mu \mathrm{g} /(\mathrm{kg} \mathrm{min})$ continuously from immediately before reperfusion until 1 hour after reperfusion. They reported that this treatment produced a significant reduction in myocardial infarct and risk areas and an improvement in cardiac function 1 month after. In addition, J-WIND, ${ }^{19}$ a large clinical trial, reported similar results: carperitide in patients with myocardial infarction reduced the infarct size by $14.7 \%$, increased left ventricular ejection fraction in the chronic stage by $5.1 \%$, and decreased reperfusion injury by $25.9 \%$. These reports strongly suggest the possibility of an inhibitory effect of ANP on ischemia-reperfusion injury.
In both reports, however, the timing of ANP administration was after reperfusion or immediately before reperfusion. In contrast, ANP administration in our experiments was begun immediately after ischemia. Naturally, in the J-WIND study of patients with acute myocardial infarction, it was impossible to administer ANP either before or during cardiac ischemia. In clinical situations, ANP can be administered before the onset of ischemia only during cardiac surgical procedures.

We investigated the effects of ANP on ischemiareperfusion injury associated with cardiac surgery by using an experimental model designed to include aortic crossclamping, cardioplegic arrest, aortic declamping, and reperfusion. It is a widely accepted that the potential mechanisms of development of the stunned myocardium are that calcium overload and presence of free radicals may play a role. ${ }^{20}$ It has been reported that vasodilators such as nitric oxide, carbon monoxide, and natriuretic peptides inhibit an increase in calcium ion concentrations in the vascular smooth muscle by using cGMP as the second messenger. ${ }^{21-23}$ In our study, myocardial and blood cGMP concentrations were increased after administration of ANP in the ischemic condition, and myocardial calcium concentrations were significantly decreased during reperfusion. We therefore believe that ANP directly acts on the myocardium and inhibits calcium overload through cGMP to improve the stunned myocardium. From the results of this study, we presume that ANP synthesizes cGMP even in 


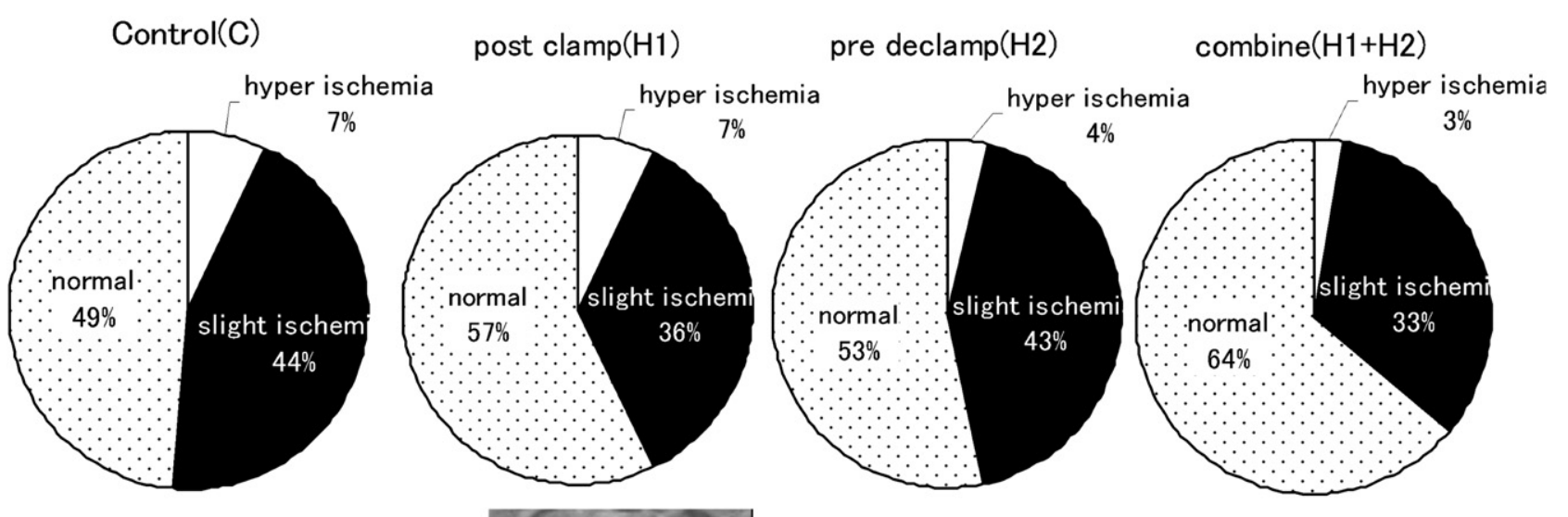

normal (-)

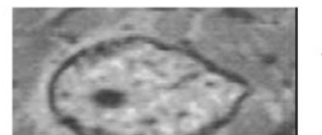

slight ischemia (+)
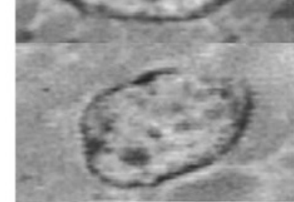

Mild aggregation of chromatin, and relatively

homogeneously stained nuclei

No aggregation of chromatin, round nuclear

bodies, and homogeneously stained nuclei

High aggregation of chromatin, but presence of

stained nuclear body

hyper ischemia $(++)$

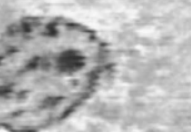

irreversible ischemia $(+++)$

\author{
stained nuclear body
}

High aggregation of chromatin, and absence of stained nuclear body

FIGURE 7. Nuclear chromatin grades and ischemic changes in nuclear chromatin. Nuclear chromatin in myocardial cells were observed with light microscopy and classified according to 4 grades: normal (-), slight ischemia (+), hyperischemia (+H), irreversible ischemia (+H). Ischemic changes were inhibited in treatment groups $(\mathrm{H} 1+\mathrm{H} 2$ more so than $\mathrm{H} 1$ and $\mathrm{H} 2)$. All 4 groups were treated with cardioplegic solution, so incidence of irreversible ischemic change was $0 \%$.

pig cardiac myocytes and that this synthesis inhibits an increase in calcium ion concentration. Electron microscopy showed that mitochondria and myocardial fibers were preserved, whereas abnormal changes in nuclear chromatin were inhibited. These findings are considered to reflect inhibition of ischemia-reperfusion injury (calcium ion overload) by the various effects of cGMP. Because mitochondria were preserved, production of ATP was maintained. The residual myocardial ATP may have increased because of decrease in the amount of ATP used for excretion of calcium.

In a previous study, ${ }^{18}$ the timing of ANP administration was only after aortic crossclamping. In light of the hypothesis that ischemia-reperfusion injury might occur during reperfusion, it was expected in this experiment that more inhibitory effect on myocardial calcium overload would be obtained by changing the timing of ANP administration from immediately after ischemia (group H1) to immediately before reperfusion (group $\mathrm{H} 2$ ). Calcium concentration tended to decrease to a greater extent in group $\mathrm{H} 1$ than in group $\mathrm{H} 2$, however, with an increase in the concentration of myocardial cGMP (there was no significant difference, but it showed tendency to decrease with ANP, H1 $P<.1035$ vs $\mathrm{C}$ and $\mathrm{H} 2 P<.2673$ vs $\mathrm{C}$ ). The higher myocardial cGMP concentration in group $\mathrm{H} 2$ can be attributed to the fact that the delay between ANP administration and cardiac muscle extraction was shorter in this group than in group H1. The calcium concentration decreased more significantly in group $\mathrm{H} 1+\mathrm{H} 2$ than in group $\mathrm{H} 2$. In addition, calcium concentration decreased to a greater extent in group $\mathrm{H} 2$ than in group H1, although the difference was not significant. The possibility that the $\mathrm{H} 1$ group treatment is more effective than $\mathrm{H} 2$ group cannot be denied. In an investigation by Marban and associates, ${ }^{20}$ time-related change in calcium concentration during ischemia-reperfusion was measured with Langendorff ferret heart models. As shown in Figure 8, calcium increase was observed more remarkably before reperfusion (during ischemia) than immediately after reperfusion, defying our expectations; calcium increase immediately after reperfusion was mild, and then calcium concentration decreased. This indicates that myocardial calcium increase occurred mainly during ischemia. Thus to 


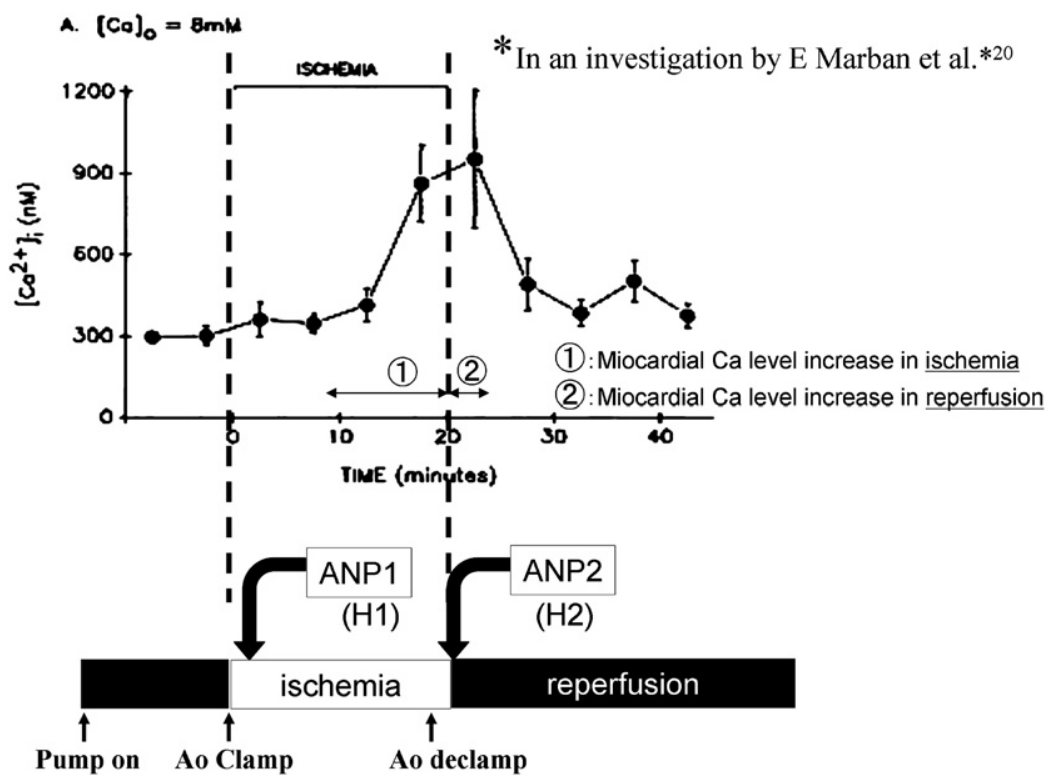

FIGURE 8. Time course of changes in calcium $(\mathrm{Ca})$ concentration $\left([\mathrm{Ca}],\left[\mathrm{Ca}^{2+}\right]\right)$ during ischemia-reperfusion. Increase in calcium was more remarkable before reperfusion (during ischemia, 1 ) than immediately after reperfusion (2), contrary to our expectations. There was slight increase immediately after reperfusion, and then levels decreased. Thus myocardial calcium increase occurred mainly during ischemia. Data from Marban and associates. ${ }^{20}$ ANP, Atrial natriuretic peptide.

alleviate reperfusion injury by inhibiting calcium increase, ANP administration during ischemia may be more effective than before reperfusion. This may be why calcium concentration decreased more in group $\mathrm{H} 1$ than in group $\mathrm{H} 2$.

This experiment was designed with an eye to clinical application in cardiac surgery, and cardioplegia was therefore used in all animals. To investigate the effect of ANP alone on ischemia-reperfusion injury, an investigation is desired in which aortic crossclamping time is prolonged without cardioplegia. Although left ventricular function was not measured in this study, ANP was shown to be effective in the protection of cardiac muscle. We plan to investigate the effect of ANP on left ventricular function in the future.

On the basis of the satisfactory results of this experiment, the clinical application was approved by the ethical review board of Nihon University Itabashi Hospital and has already started as "hANP shot." Thus far we have obtained satisfactory results. ANP is expected to be used as supportive therapy for patients with long aortic crossclamping times or those with difficulties in weaning from CPB.

\section{CONCLUSIONS}

ANP acts directly on the myocardium through cGMP. ANP inhibits ischemia-reperfusion injury by decreasing myocardial calcium concentration. Ischemia-reperfusion injury is inhibited with equal effectiveness when administered either during ischemia or immediately before reperfusion.

\section{References}

1. Kanagawa K, Matsuo H. Purification and complete amino acid sequence of alphahuman atrial natriuretic polypeptide. Biochem Biophys Res Commun. 1984;118: 131-9.

2. Maack T, Marion DN, Camargo MJ, Kleinert HD, Laragh JH, Vaughan ED Jr, et al. Effects of auriculin (atrial natriuretic factor) on blood pressure, renal function and the renin-aldosterone system in dogs. Am J Med. 1984;77:1069-75.

3. Ishihara T, Aisaka K, Hattori Y, Hamasaki S, Morita M, Noguchi T, et al. Vasodilatory and diuretic actions of $\alpha$-human atrial natriuretic polypeptide $(\alpha$ hANP). Life Sci. 1985;36:1205-15.

4. Weder AB, Sekkarie MA, Takiyyuddin M, Schork NJ, Julius S. Antihypertensive and hypotensive effects of atrial natriuretic factor in men. Hypertension. 1987;10: 582-9.

5. Wedel B, Garbers D. The guanylyl cyclase family at Y2K. Annu Rev Physiol. 2001;63:215-33.

6. Venugopal J. Cardiac natriuretic peptides-hope or hype? J Clin Pharm Ther. 2001;26:15-31.

7. Ito T, Yoshimura M, Nakamura S, Nakayama M, Shimasaki Y, Harada E, et al. Inhibitory effect of natriuretic peptides on aldosterone synthase gene expression in cultured neonatal rat cardiocytes. Circulation. 2003;107:807-10.

8. Mizuno Y, Yoshimura M, Yasue H, Sakamoto T, Ogawa H, Kugiyama K, et al. Aldosterone production is activated in failing ventricle in humans. Circulation. 2001;103:72-7.

9. Kishimoto I, Rossi K, Garbers DL. A genetic model provides evidence that the receptor for atrial natriuretic peptide (guanylyl cyclase-A) inhibits cardiac ventricular myocyte hypertrophy. Proc Natl Acad Sci U S A. 2001;98:2703-6.

10. Li Y, Kishimoto I, Saito Y, Harada M, Kuwahara K, Izumi T, et al. Guanylyl cyclase-A inhibits angiotensin type $1 \mathrm{~A}$ receptor-mediated cardiac remodeling, an endogenous protective mechanism in the heart. Circulation. 2002;106: 1722-8.

11. Tokudome T, Horio T, Kishimoto I, Soeki T, Mori K, Kawano Y, et al. Calcineurin-nuclear factor of activated $\mathrm{T}$ cells pathway-dependent cardiac remodeling in mice atrial and brain natriuretic peptides. Circulation. 2005;111:3095-104.

12. Sezai A, Shiono M, Orime Y, Hata H, Hata M, Negishi N, et al. Low-dose continuous infusion of human atrial natriuretic peptide during and after cardiac surgery. Ann Thorac Surg. 2000;69:732-8.

13. Sezai A, Hata M, Wakui S, Shiono M, Negishi N, Kasamaki Y, et al. Efficacy of low-dose continuous infusion of alpha-human atrial natriuretic peptide (hANP) during cardiac surgery: possibility of postoperative left ventricular remodeling effect. Circ J. 2006;70:1426-31. 
14. Sezai A, Hata M, Wakui S, Niino T, Takayama T, Hirayama A, et al. Efficacy of continuous low-dose hANP administration in patients undergoing emergent coronary artery bypass grafting for acute coronary syndrome. Circ J. 2007;71: 1401-7.

15. Laragh JH. Atrial natriuretic hormone, the renin-aldosterone axis, and blood pressure-electrolyte homeostasis. N Engl J Med. 1985;313:1330-40.

16. Stein BC, Levin RI. Natriuretic peptides: physiology, therapeutic potential, and risk stratification in ischemic heart disease. Am Heart J. 1998;135:914-23.

17. Kuga H, Ogawa K, Oida A, Taguchi I, Nakatsugawa M, Hoshi T, et al. Administration of atrial natriuretic peptide attenuates reperfusion phenomena and preserves left ventricular regional wall motion after direct coronary angioplasty for acute myocardial infarction. Circ J. 2003;67:443-8.

18. Wakui S. Experimental study on myocardial protection by adjunct use of carperitide (hANP)in cardiac surgery. Ann Thorac Cardiovasc Surg. 2005;11:12-20.

19. Kitakaze M, Asakura M, Kim J, Shintani Y, Asanuma H, Hamasaki T, et al. Human atrial natriuretic peptide and nicorandil as an adjunct to reperfusion therapy for acute myocardial infarction with ST-segment elevation: the randomised J-WIND (Japan-Working Groups of Acute Myocardial Infarction for the Reduction of Necrotic Damage) trials. Lancet. 2007;370:1483-93.

20. Marban E, Kitakaze M, Koretsune Y, Yue DT, Chacko VP, Pike MM. Quantification of [Ca2+] in perfused hearts: critical evaluation of the 5F-BAPTA and nuclear magnetic resonance method as applied to the study of ischemia and reperfusion. Circ Res. 1990;66:1255-67.

21. Winquist RJ, Faison EP, Waldman SA, Schwartz K, Murad F, Rapoport RM. Atrial natriuretic factor elicits an endothelium-independent relaxation and activates particulate guanylate cyclase in vascular smooth muscle. Proc Natl Acad Sci U S A. 1984;81:7661-4.

22. Munzel T, Feil R, Mulsch A, Lohmann SM, Hormann F, Walter U. Physiology and pathophysiology of vascular signaling controlled by guanosine $3^{\prime}, 5^{\prime}$-cyclic monophosphate-dependent protein kinase. Circulation. 2003;108:2172-83.

23. Gross GJ, Kersten JR, Warltier DC. Mechanisms of postischemic contractile dysfunction. Ann Thorac Surg. 1999;68:1898-904. 